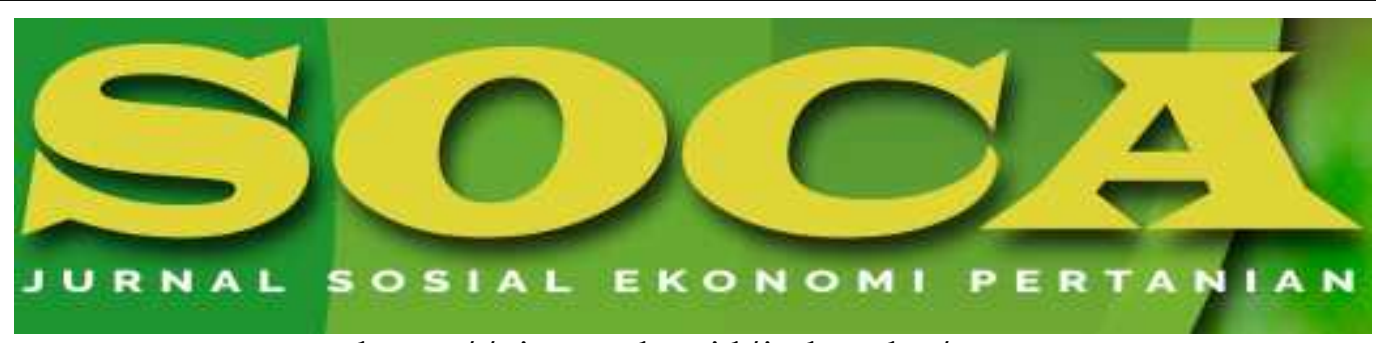

https://ojs.unud.ac.id/index.php/soca

\title{
ANALISIS PENDAPATAN USAHATANI MINAPADI DI KABUPATEN SUKOHARJO
}

\author{
Diyah Tri Lestari, Djoko Sumarjono dan Titik Ekowati \\ Program Studi S1 Agribisnis, Fakultas Peternakan dan Pertanian, \\ Universitas Diponegoro, Tembalang, Semarang, Jawa Tengah \\ Email:diyahtri29@gmail.com, Telepon/HP:085881105830
}

Kata Kunci:
minapadi, padi,
pendapatan
bersih,
usahatani.

Kata Kunci: minapadi, padi, pendapatan usahatani.

\begin{abstract}
Abstrak
Permintaan terhadap komoditas padi tinggi, sehingga produktivitas padi perlu ditingkatkan. Salah satu cara yang ditempuh untuk meningkatkan produktivitas adalah diversifikasi lahan melalui minapadi. Kabupaten Sukoharjo menjadi salah satu lokasi pengembangan minapadi. Peralihan dari sistem monkultur padi ke minapadi memberikan perubahan bagi petani baik dari input, biaya dan pendapatan. Tujuan penelitian ini untuk menganalisis pendapatan minapadi dan monokultur padi, profitabilitas minapadi dan monokultur padi, perbedaan pendapatan bersih minapadi dan monokultur padi, perbedaan profitabilitas minapadi dan monokultur padi serta perbedaan profitabilitas minapadi dengan suku bunga deposito bank. Metode penelitian yang digunakan adalah sensus dengan 33 responden yang menerapkan minapadi dan sebelumnya menerapkan budidaya monokultur padi. Penelitian dilaksanakan pada November-Desember 2018 di Desa Geneng Kecamatan Gatak dan Desa Dalangan Kecamatan Tawangasari Kabupaten Sukoharjo. Pengumpulan data dilakukan dengan wawancara menggunakan kuesioner. Analisis data yang digunakan adalah analisis pendapatan bersih dan analisis profitabilitas. Uji hipotesis yang digunakan adalah uji beda paired sample t test dan one sample t test. Hasil penelitian menunjukkan pendapatan bersih minapadi (Rp 11.417.133/musim/ $4.152 \mathrm{~m}^{2}$ ) lebih besar dari pendapatan bersih monokultur padi (Rp $7.564 .842 /$ musim/4.152 $\mathrm{m}^{2}$ ), profitabilitas minapadi (77.69\%) dan profitabilitas monokultur padi (142.86\%) berbeda secara signifikan. Profitabilitas minapadi lebih besar dari pada suku bunga deposito bank $(5,5 \%)$.
\end{abstract}


ANALYSIS OF MINAPADI BUSINESS INCOME IN SUKOHARJO DISTRICT

\section{Keywords:}

farming, minapadi, net income, paddy

\begin{abstract}
Abstrak
The demand of paddy commodity is high, so paddy productivity needs to be increased. One way to increase productivity is land diversification through minapadi. Sukoharjo Regency is one of the development sites of Minapadi. The transition from the paddy monoculture system to minapadi provides a change for farmers both from technical cultivation, inputs, costs and income. This research aims to analyze net income of minapadi and paddy monoculture, profitability of minapadi dan paddy monoculture, comparation between net income of minapadi and paddy monoculture, comparation between profitability of minapadi and paddy monoculture, and analyze comparation between profitability of minapadi with bank deposit rate. Research method is sencus with 33 repondents who applied minapadi and previoudly carried out paddy monoculture. The research was conducted in November-Desember 2018 in the Gatak and Tawangsari District, Sukoharjo Region. Data were collected by interview using quetionnaires. Data were analyzed by net income analyze and profitability analyze. Hypothesis testing by paired sample t test and one sample $t$ test. The results showed that net income of minapadi (IDR $11,417,133 /$ season/4,152 $\mathrm{m}^{2}$ ) greater than net income of paddy monoculture (IDR 7,564,842/season/4,152 $\mathrm{m}^{2}$ ), minapadi profitability (77.69\%) and paddy monoculture profitability (142.86\%) was a significant different. Profitability of minapadi is greater than bank deposit rate (5.5\%).
\end{abstract}

How to Cite (APA 6 th $^{\text {th }}$ Sty):

Lestari, D. T., Sumarjono, D., \& Ekowati, T. (2019). Analisis Pendapatan Usahatani Minapadi di Kabupaten Sukoharjo. SOCA: Jurnal Sosial Ekonomi Pertanian, 13(3), 304-316. https://doi.org/https://doi.org/10.24843/SOCA.2019.v13.i03.p02

\title{
PENDAHULUAN
}

Minapadi dilaksanakan di Indonesia sejak 1970-an dengan teknik sederhana sehingga belum menghasilkan keuntungan yang optimal (Akbar, 2017). Minapadi kembali digalakkan melalui pengembangan minapadi di Kabupaten Sleman pada tahun 2014 yang mendapat apresiasi dari Food and Agriculture Organization (FAO). Food and Agriculture Organization (FAO) bersama Pemerintah sejak tahun 2015 kembali mengembangkan minapadi melalui program National Training on Promote Scaling-up of Innovative Rice-Fish Farming and Climate Resilient Tilapia Pond Culture Practice for Blue Growth in Asia yang dilanjutkan hingga tahun 2018.

Minapadi sebagai upaya diversifikasi lahan untuk meningkatkan produktivitas padi yang permintaanya bersifat inelastis. Minapadi merupakan 
integrasi budidaya padi dan ikan dalam satu lahan. Output yang dihasilkan dua macam sehingga mampu mengurangi risiko apabila terjadi kegagalan pada salah satu komoditas. Minapadi dinilai berkontribusi pada peningkatan produktivitas lahan, yang berdampak pada peningkatan pendapatan bersih, selain itu kelestarian lingkungan terjaga karena minimalisir penggunaan pupuk.

Penelitian Akbar (2017) menunjukkan bahwa penerapan minapadi oleh petani dapat meningkatkan pendapatan, dari semula Rp 46.589.495/tahun menjadi Rp 75.401.269/tahun.

Penelitian Julistia (2017) menunjukkan adanya perbedaan penggunaaan input antara minapadi dan monokultur padi. Pendapatan minapadi lebih tinggi dari monokultur padi sehingga minapadi lebih menguntungkan. Umur petani dan pengalaman budidaya menjadi faktor yang mempengaruhi keputusan memilih minapadi.

Hasil penelitian Saputra et al. (2017) menunjukkan tidak ada perbedaan varietas budidaya minapadi dan non minapadi. Sistem tanam minapadi adalah jajar legowo sedangkan non minapadi dengan sistem tanam konvensional. Produktivitas dan pendapatan minapadi lebih tinggi dari non minapadi. Penggunaan modal minapadi lebih efisien.

Penelitian Tysno (2018) menunjukkan biaya total usahatani minapadi lebih besar dari non minapadi dengan proporsi biaya tunai yang lebih besar dari biaya non tunai. Tambahan produksi ikan meningkatkan pendapatan atas biaya tunai dan biaya total minapadi dibandingkan non minapadi. $\mathrm{R} / \mathrm{C}$ ratio biaya tunai dan $\mathrm{R} / \mathrm{C}$ ratio biaya non tunai minapadi lebih tinggi dari non minapadi. Tenaga kerja dalam minapadi lebih banyak dibandingkan non minapadi.

Penelitian Lantarsih (2017) menunjukkan pengembangan minapadi memiliki kekuatan, kelemahan, peluang dan ancaman. Kekuatan yang dimiliki meliputi peningkatan produksi, pendapatan, kesuburan tanah, keterampilan petani, serta penurunan hama dan gulma. Kelemahan meliputi keterbatasan alat, tenaga kerja dan modal. Peluang minapadi meliputi ketersediaan lahan, air, transportasi, peluang pasar, informasi teknologi serta akses bibit ikan. Ancaman meliputi, akses kredit yang rendah, ketersediaan tenaga kerja, kualitas air dan kenaikan harga input.

Salah satu lokasi pengembangan minapadi adalah Kabuputen Sukoharjo. Kabupaten Sukoharjo merupakan sentra penghasil padi dengan luas lahan mencapai 20.158 ha, selain itu menjadi salah satu pusat lumbung padi nasional dengan 50\% lahan sawah potensial untuk minapadi. Produktivitas padi kabupaten Sukoharjo mencapai 74,66 kw/ ha (Badan Pusat Statistika, 2018).

Kajian megenai perubahan dari monokultur ke minapadi menarik untuk dibahas. Perbedaan dari penelitian sebelumnya adalah pembahasan profitabilitas untuk mengetahui kelayakan minapadi. Tujuan penelitian ini untuk menganalisis pendapatan bersih minapadi dan monokultur padi, profitabilitas minapadi dan monokultur padi, perbedaan antara pendapatan bersih minapadi dan monokultur padi, perbedaan antara profitabilitas minapadi dan monokultur padi, serta perbedaan profitabilitas minapadi dengan suku bunga deposito bank. 


\section{METODE PENELITIAN}

Metode penelitian yang digunakan adalah sensus. Sensus adalah pengambilan data dari seluruh anggota dalam populasi (Sugiyono, 2008). Penelitian dilakukan pada seluruh petani minapadi di Kabupaten Sukoharjo yang musim sebelumnya menerapkan monokultur padi. Total responden 33 yang terdiri dari 27 responden di Desa Dalangan Kecamatan Tawangsari dan 6 responden di Desa Geneng Kecamatan Gatak. Data yang digunakan adalah data primer hasil wawancara menggunakan kuesioner dan data sekunder hasil studi pustaka buku, jurnal, maupun catatan dari Dinas Pertanian dan Badan Pusat Statistika.

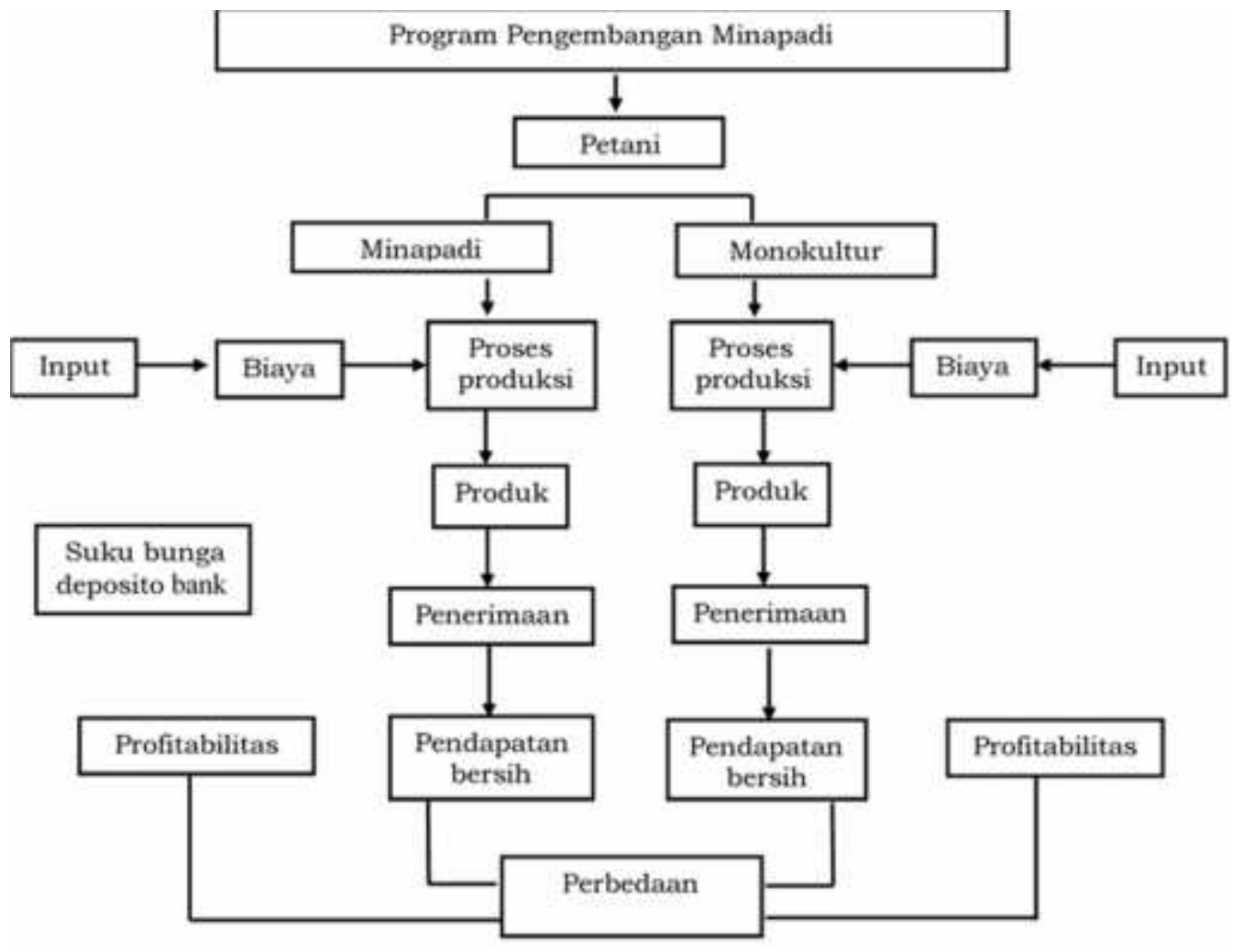

Gambar 1. Kerangka Pemikiran

Berdasarkan Ilustrasi 1. ditunjukkan bahwa FAO bersama pemerintah mengembangkan minapadi padi di Kabputen Sukoharjo. Petani minapadi yang semula menerapakan monokultur padi, sehingga petani mengalami perubahan dari budidaya, input, biaya, produk, penerimaan, pendapatan bersih dan profitabilitas.

Analisis data menggunakan analisis pendapatan dan analisis profitabilitas. Analisis pendapatan menggunakan 3 rumus yaitu rumus pendapatan bersih, biaya dan penerimaan. Berikut rumus analisis pendapatan menurut Ekowati et al. (2014):

$\mathrm{PB}=\mathrm{PK}-\mathrm{BU} . .$.
$\mathrm{BU}=\mathrm{BAL}-\mathrm{UTKK}$
$\mathrm{PK}=\mathrm{PY} . \mathrm{Y} \ldots \ldots . .$. 
Keterangan:

$\mathrm{PB}=$ Pendapatan Bersih (Rp/musim/luas lahan)

$\mathrm{PK}=$ Penerimaan $(\mathrm{Rp} / \mathrm{musim} /$ luas lahan $)$

$\mathrm{BU}$ = Biaya Mengusahakan (Rp/musim/luas lahan)

$\mathrm{BAL}$ = Biaya Alat Luar (Rp/musim/luas lahan)

UTKK = Upah Tenaga Kerja Keluarga $(\mathrm{Rp} / \mathrm{HOK})$

$\mathrm{PY} \quad=$ Harga Produk $(\mathrm{Rp})$

$\mathrm{Y} \quad=$ Produksi $(\mathrm{kg})$

Analisis data profitabilitas menurut Ekowati et al. (2014):

Profitabilitas $=\frac{\mathrm{BU}}{\mathrm{PB}} \times 100 \%$

Keterangan:

$\mathrm{BU}=$ Biaya Mengusahakan

(Rp/musim/ luas lahan)

$\mathrm{PB}=$ Pendapatan Bersih (Rp/ musim/ luas lahan)

Uji hipotesis diawali dengan uji normalitas data Kolmogorov smirnov untuk mengetahui distribusi data yang selanjutnya digunakan untuk menentukan jenis uji (Ghozali 2011). Data berdistribusi normal menggunakan uji parametrik, sedangkan data berdistribusi tidak normal digunakan uji non parametrik.

Hipotesis 1

HO: $\mu \mathrm{a}-\mu \mathrm{b}=0$, pendapatan bersih minapadi sama dengan pendapatan bersih monokultur padi

$\mathrm{Hl}: \mu \mathrm{b}-\mu \mathrm{a}>0$, pendapatan bersih minapadi lebih besar daripada pendapatan bersih monokultur padi.

Hipotesis 1 di uji dengan uji beda paired sample t test untuk distribusi data normal, jika data tidak berdistribusi normal digunakan uji beda wilcoxon.

Hipotesis 2:

HO: $\mu \mathrm{x}-\mu \mathrm{y}=0$, profitabilitas minapadi sama dengan profitabilitas monokultur padi

H1: $\mu \mathrm{x}-\mu \mathrm{y} \neq 0$, profitabilitas minapadi berbeda dengan profitbilitas monokultur padi

Hipotesis 2 di uji dengan uji beda paired sample t test untuk distribusi data normal, jika data tidak berdistribusi normal digunakan uji beda wilcoxon.

Hipotesis 3

HO: $\mu$ s $-\mu=0$, profitabilitas minapadi sama dengan suku bunga deposito bank. H1: $\mu \mathrm{s}-\mu>0$, profitabilitas minapadi lebih besar dari suku bunga deposito bank.

Hipotesis 3 di uji dengan uji one sample t test untuk distribusi data normal, jika data tidak berdistribusi normal digunakan uji beda wilcoxon. berikut:

Kaidah penerimaan dan penolakan hipotesis tersebut diuraikan sebagai 
Nilai signifikansi $\leq$ 0,05 menunjukan HO ditolak dan Hl diterima, sedangkan nilai signifikansi > 0,05 maka HO di diterima dan Hl ditolak (Santoso, 2016).

\section{HASIL DAN PEMBAHASAN}

\section{Gambaran Umum}

Kabupaten Sukoharjo terletak di Provinsi Jawa Tengah dengan batas administrasi sebelah utara Kota Surakarta dan Kabupaten Karanganyar, sebelah selatan Kabupaten Gunung Kidul dan Kabupaten Wonogiri, sebelah timur Kabupaten Karanganyar, serta sebelah barat Kabupaten Boyolali dan Kabupaten Klaten.

Minapadi dilaksanakan di dua lokasi yaitu Desa Geneng Kecamatan Gatak dan Desa Dalangan Kecamatan Tawangsari. Luas lahan Kecamatan Gatak 1.947 atau $4,17 \%$ dari total luas Kabupaten Sukoharjo yang terdiri dari 1.209 ha lahan sawah, 607 ha pekarangan dan 131 ha lahan lain. Total luas Kecamatan Tawangsari adalah 3.998 yang terdiri dari 1.661 lahan sawah dan 2.321 bukan lahan sawah. Kabupaten Sukoharjo memiliki produktivitas padi tertinggi di Jawa Tengah pada tahun 2017 yaitu 74,66 kw/ha dari Luas sawah 52.596 ha dan produksi padi $392.660 \mathrm{kw}$. Nilai tersebut menunjukkan Kabupaten Sukoharjo mampu menjadi salah satu penyangga pangan di Jawa Tengah dengan jumlah produktivitas tersebut.

\section{Karakteristik Responden}

Karakteristik adalah ciri khas atas keragaman responden. Karakteristik responden meliputi jenis kelamin, usia, tingkat pendidikan, pekerjaan, luas lahan, lama usahatani, dan status kepemilikan lahan. Karakteristik responden disajikan dalam Tabel 1. Tabel 1 menunjukkan seluruh responden berjenis kelamin laki-laki. Rata-rata usia responden adalah 56 tahun yang tergolong tua dan melebihi usia produktif. Usia produktif petani berkisar antara 30-49 tahun. Tingkat pendidikan responden rata-rata adalah SD yang tergolong masih rendah. Profesi sebagai petani merupakan pekerjaan utama oleh $63,63 \%$ responden dan $36,37 \%$ memiliki pekerjaan lain sebagai sumber utama pendapatan. Pekerjaan utama atau sampingan dapat dilihat dari lama curahan waktu yang diberikan. Rata-rata lama usahatani adalah 13,5 tahun. Rentang waktu tersebut petani memiliki banyak pengalaman dan pemahaman usahatani. Rata-rata luas lahan responden adalah 4152 m2 yang digolongkan lahan sempit. Menurut Pratiwi dan Rondhi (2018) luas lahan digolongkan menjadi 4 yaitu $<2.500 \mathrm{~m} 2$ tergolong sempit, 2.500-5.000 tergolong agak sempit, $5.000-7.500 \mathrm{~m} 2$ tergolong sedan dan 10.000-20.000 m2 tergolong luas. Luas lahan sebagai salah satu faktor penentu produksi usahatani. Semakin luas lahan yang dikelola, peluang petani memperoleh hasil produksi optimal semakin tinggi yang akan berdampak pada pendapatan. Kepemilikan lahan dibedakan menjadi 3 jenis yaitu lahan sendiri, sewa dan sakap. Status kepemilikan lahan berdampak pada investasi, penggunaan biaya, dan pendapatan. Penguasaan lahan sebagai ilustrasi pemeratan faktor produksi di tingkat petani. Menurut Pratiwi dan Rondhi (2018) semakin tinggi pendapatan semakin tinggi tingkat penguasaan lahan oleh petani. Pendapatan yang tinggi mampu mendorong petani berinvestasi setelah kebutuhan pokok terpenuhi, salah satu investasi tersebut berupa lahan. 
Tabel 1. Jumlah dan Persentase Responden Berdasarkan Karakteristik Responden.

\begin{tabular}{|c|c|c|}
\hline Uraian & Jumlah & Persentase \\
\hline & ------ jiwa ------ & -------- \% -------- \\
\hline \multicolumn{3}{|l|}{ Jenis Kelamin } \\
\hline - Laki -Laki & 33 & 100 \\
\hline \multirow{2}{*}{ - Perempuan } & 0 & 0 \\
\hline & 33 & 100 \\
\hline \multicolumn{3}{|l|}{ Usia (tahun) } \\
\hline$-30-39$ & 1 & 3,03 \\
\hline$-40-49$ & 9 & 27,27 \\
\hline$-50-59$ & 10 & 30,30 \\
\hline$-60-69$ & 10 & 30,30 \\
\hline \multirow[t]{2}{*}{$\begin{array}{l}-\quad 70-79 \\
\end{array}$} & 3 & 9,09 \\
\hline & 33 & 100 \\
\hline \multicolumn{3}{|l|}{ Tingkat Pendidikan } \\
\hline - Tidak Tamat & 2 & 6,06 \\
\hline$-\mathrm{SD}$ & 18 & 54,54 \\
\hline - SMP & 4 & 12,12 \\
\hline - SMA/SMK & 7 & 21,21 \\
\hline \multirow{2}{*}{ - $\quad \mathrm{S} 1$} & 2 & 6,06 \\
\hline & 33 & 100 \\
\hline \multicolumn{3}{|l|}{ Pekerjaan Utama } \\
\hline - Petani & 21 & 63,63 \\
\hline - Buruh & 4 & 12,12 \\
\hline - Wiraswasta & 1 & 12,12 \\
\hline - Perangkat Desa & 3 & 9,09 \\
\hline \multirow{2}{*}{ - PNS } & 4 & 3,03 \\
\hline & 33 & 100 \\
\hline \multicolumn{3}{|l|}{ Lama Usahatani (tahun) } \\
\hline$-1-10$ & 14 & 45,45 \\
\hline$-11-20$ & 13 & 42,42 \\
\hline$-21-30$ & 3 & 9,09 \\
\hline$-31-40$ & 0 & 0 \\
\hline \multirow[t]{2}{*}{$-\quad 41-50$} & 1 & 3,03 \\
\hline & 33 & 100 \\
\hline \multicolumn{3}{|l|}{ Luas Lahan $\left(\mathrm{m}^{2}\right)$} \\
\hline$-\quad 1.000-5.000$ & 25 & 75,76 \\
\hline$-\quad>5.000-10.000$ & 6 & 18,18 \\
\hline \multirow[t]{2}{*}{$-\quad>10.000$} & 2 & 6,06 \\
\hline & 33 & 100 \\
\hline \multicolumn{3}{|l|}{ Status Kepemilikan Lahan } \\
\hline - Milik Sendiri & 17 & 51,52 \\
\hline - Sewa & 7 & 21,21 \\
\hline \multirow[t]{2}{*}{ - Sakap } & 9 & 27,27 \\
\hline & 33 & 100 \\
\hline
\end{tabular}

Sumber: Data primer penelitian yang telah diolah, 2019.

\section{Investasi dan Penyusutan.}

Investasi monokultur padi beragam seperti lahan, cangkul, sprayer, sorok, ember, diesel, garpu, dan traktor, setelah penerapan minapadi investasi alat bertambah yaitu waring, pipa dan bambu. Penambah alat sebagai bentuk penyesuaian keperluan budidaya. Investasi merupakan pendanaan awal usahatani 
yang digunakan terus menerus. Total investasi petani dengan rata-rata luas lahan $4.152 \mathrm{~m} 2$ saat minapadi sebesar Rp 169.640.640 dan monokultur padi sebesar Rp 169.222.879 dengan peningkatan investasi minapadi sebesar 0,25.

Kinerja peralatan produksi akan menurun setiap digunakan, hal ini disebut penyusutan. Penyusutan dihitung berkala dan diperhitungkan sebagai biaya akibat penggunaan, penurunan kemampuan maupun lama kepemilikan. Investasi lahan tidak memiliki nilai penyusutan karena nilai lahan semakin meningkat tiap tahun. Penyusutan minapadi sebesar $\mathrm{Rp}$ 341.632/musim/ $4.152 \mathrm{~m} 2$ sedangkan monokultur padi sebesar Rp 191.504/musim /4.152 m2 dengan peningkatan $78,39 \%$. Penyusutan minapadi juga meningkat searah dengan peningkatan investasi. Sesuai pendapat Julistia (2017) bahwa alat pertanian minapadi dan monokultur padi berbeda, jenis dan jumlahnya yang berbeda membuat nilai penyusutan berbeda yaitu penyusutan minapadi lebih besar karena jenis dan jumlah peralatan yang lebih banyak.

\section{Produktivitas}

Produktivitas merupakan proses pengubahan faktor produksi menjadi sebuah produk. Produktivitas mencerminkan perbandingan antara total produksi dengan luasan lahan. Rincian produktivitas minapadi dan monokultur padi disajikan dalam Tabel 2.

Tabel 2. Luas Lahan, Produksi dan Produktivitas Usahatani Minapadi dan Monokultur Padi

\begin{tabular}{lccc}
\hline Uraian & Luas Lahan & Produksi & $\begin{array}{c}\text { Produktivitas } \\
\text {-------- } \mathrm{mg} / \mathrm{m} 2 \text {--- }\end{array}$ \\
\hline Minapadi & & $-----\mathrm{kg}-----$ & 0,86 \\
1. Padi & 3.736 & 3.246 & 1,12 \\
$\begin{array}{l}\text { 2. Ikan } \\
\text { Monokultur Padi }\end{array}$ & 415 & 469 & 0,77 \\
1. Padi & 4.152 & 3.166 & \\
\hline
\end{tabular}

Sumber: Data primer penelitian yang telah diolah, 2019.

Produktivitas padi dari monokultur padi ke minapadi mengalami peningkatan sebesar $11,69 \%$. Sesuai penelitian Julistia (2015) bahwa melalui minapadi terjadi peningkatan produktivitas lahan dari $5.652 \mathrm{~kg} /$ ha menjadi $7.612 \mathrm{~kg} / \mathrm{ha}$. Luas monokultur padi dan minapadi sama, tetapi proporsi minapadi sebesar $90 \%$ atau $3.736 \mathrm{~m}^{2}$ untuk budidaya padi dan $10 \%$ atau $415 \mathrm{~m}^{2}$ untuk budidaya ikan. Luas areal tanam padi dalam minapadi berkurang 10,02\% dari total semula, tetapi lahan tetap memproduksi padi dengan peningkatan produksi sebesar $2,53 \%$ dibandingkan sistem monokultur. Menurut Tysno (2018) budidaya minapadi disebut berhasil ketika produksi padi minimal sama dengan produksi sebelum minapadi. Kemampuan lahan dalam produksi semakin baik saat penerapan minapadi. Upaya peningkatan produktivitas dicapai melalui perbaikan kondisi tanah serta penanganan serangan hama dan gulma secara intensif. Produktivitas padi sistem monokultur padi telah melebihi standar produktivitas di Sukoharjo, begitu pula produktivitas padi pada sistem minapadi. Berdasarkan data Badan Pusat Statistika (2018) produktivitas padi di Kabupaten Sukoharjo mencapai 0,75 kg/m². 
Produktivitas ikan menurut estimasi Dinas Pertanian Dan Perikanan Sukoharjo sebesar $0,1 \mathrm{~kg} / \mathrm{m}^{2}$, sehingga produktivitas ikan hasil budidaya minapadi sebesar $1,12 \mathrm{~kg} / \mathrm{m}^{2}$ telah melebihi estimasi produktivitas di Sukoharjo.

\section{Biaya}

Biaya merupakan seluruh pengorbanan yang dinilai dalam bentuk uang dalam kegiatan usahatani. Biaya dalam usahatani dinyatakan dengan biaya mengusahakan yang terdiri dari biaya alat luar dan biaya tenaga kerja keluarga yang diperhitungkan berdasarkan upah tenaga kerja luar keluarga. Rincian biaya minapadi dan monokultur padi disajikan pada Tabel 3.

Biaya mengusahakan minapadi lebih besar dari monokultur padi, peningkatan biaya sebesar 138,59\%/musim. Sesuai pernyataan Tysno (2018) bahwa usahatani minapadi membutuhkan biaya yang lebih besar dari monokultur padi untuk pembelian input tambahan. Perbedaan biaya timbul akibat penyesuaian kebutuhan dan hambatan yang timbul pada minapadi. Komponen input yang bertambah adalah benih ikan dan pakan ikan yang bernilai cukup besar karena harga input yang tinggi. Komponen biaya yang meningkat yaitu penyusutan, irigasi, upah tenaga kerja luar dan upah tenaga kerja keluarga.

Tabel 3. Biaya Usahatani Monokultur Padi dan Minapadi

\begin{tabular}{|c|c|c|}
\hline \multirow{2}{*}{ Uraian } & \multicolumn{2}{|c|}{ Biaya } \\
\hline & Minapadi & Monokultur Padi \\
\hline & -- Rp/musim/luas & ahan $\left(4.152 \mathrm{~m}^{2}\right)^{--}$ \\
\hline \multicolumn{3}{|l|}{ Biaya Alat Luar } \\
\hline - Penyusutan & 122.725 & 61.860 \\
\hline$-\quad \mathrm{PBB}$ & 14.990 & 9.634 \\
\hline - Sewa Lahan & 533.333 & 533.333 \\
\hline - $\quad$ Benih Padi & 204.227 & 225.515 \\
\hline - Benih Ikan & 416.237 & - \\
\hline - Pupuk & 420.308 & 695.091 \\
\hline - Pakan Ikan & 5.799 .026 & - \\
\hline - Pestisida & - & 113.844 \\
\hline - Sewa Mesin & 229.394 & 244.545 \\
\hline - Irigasi & 244.924 & 99.394 \\
\hline - Transportasi & 74.091 & 79.848 \\
\hline - UpahTenaga & 2.872 .864 & 2.343 .826 \\
\hline Kerja Luar & & \\
\hline Keluarga & & \\
\hline
\end{tabular}

\begin{tabular}{lrr} 
Biaya Tenaga Kerja Keluarga & 1.613 .542 & 851.326 \\
\hline Total Biaya Mengusahakan & 5.258 .216 & 12.545 .661
\end{tabular}

Sumber: Data primer penelitian yang telah diolah, 2019

\section{Penerimaan}

Penerimaan merupakan hasil penjualan dari sejumlah produk atau jasa dalam periode tertentu. Komponen penerimaan berasal dari jumlah produksi dikali dengan harga jual per satuan unit. Rincian penerimaan dapat dilihat dalam 
Tabel 4. Selisih penerimaan produksi padi saat minapadi dan monokultur padi sebesar Rp 1.151 .358 atau meningkat $8,1 \%$ saat minapadi. Besar penerimaan dipengaruhi oleh jumlah produksi dan harga jual. Harga jual padi rata-rata saat dan saat minapadi senilai Rp $4.700 / \mathrm{kg}$ dan monokultur padi senilai $4.500 / \mathrm{kg}$. Harga atas hasil panen petani dapat beragam karena perbedaan kualitas, waktu panen, serta cara penjualan. Selisih penerimaan total antara minapadi dan monokultur padi mencapai Rp 11.927 .903 dengan peningkatan $83,95 \%$ saat minapadi. Sesuai penelitian Julistia (2017) bahwa penerimaan total minapadi lebih besar karena adanya dua output yaitu padi dan ikan.

Tabel 4. Jumlah Produksi, Harga Jual dan Penerimaan Minapadi dan Monokultur Padi

\begin{tabular}{|c|c|c|c|}
\hline Uraian & $\begin{array}{l}\text { Jumlah } \\
\text { Produksi }\end{array}$ & Harga Jual & Total Penerimaan \\
\hline & ----- kg ----- & ----- Rp ----- & $\mathrm{Rp} / \mathrm{musim} / 4.152 \mathrm{~m}^{2}$ \\
\hline \multicolumn{4}{|l|}{ Minapadi } \\
\hline - $\quad$ Padi & 3.246 & 4.700 & 15.359 .985 \\
\hline \multirow[t]{2}{*}{ - Ikan } & 469 & 23.000 & 10.776 .545 \\
\hline & & & 26.136 .530 \\
\hline \multicolumn{4}{|l|}{$\begin{array}{l}\text { Monokultur } \\
\text { Padi }\end{array}$} \\
\hline \multirow[t]{2}{*}{ - $\quad$ Padi } & 3.166 & 4.500 & 14.208 .627 \\
\hline & & & 14.208 .627 \\
\hline
\end{tabular}

Sumber: Data primer penelitian yang telah diolah, 2019

\section{Pendapatan Bersih}

Pendapatan bersih adalah hasil penerimaan dari kegiatan usahatani yang telah dikurangi dengan biaya mengusahakan. Rincian pendapatan bersih disajikan di Tabel 5. Peningkatan pendapatan sebesar 33,74\% terjadi saat petani berpindah ke sistem minapadi. Sesuai pernyataan Saputra et al. (2017) bahwa pendapatan minapadi yang dihasilkan lebih besar dari pendapatan minapadi. Sesuai penelitian Peningkatan pendapatan merupakan hal yang baik untuk keberlanjutan usahatani. Sesuai pernyataan Cahyanti et al. (2014) indikator keberhasilan minapadi dilihat dari peningkatan pendapatan per hektar. Pendapatan pada sistem minapadi mengalami perbedaan karena perbedaan hasil produksi yaitu adanya tambahan produksi ikan pada luasan lahan yang sama dengan lahan monokultur.

Tabel 5. Penerimaan, Biaya Mengusahakan dan Pendapatan Bersih Usahatani Minapadi dan Monokultur Padi

\begin{tabular}{lccc}
\hline \multicolumn{1}{c}{ Uraian } & Penerimaan & $\begin{array}{c}\text { Biaya } \\
\text { Mengusahakan }\end{array}$ & $\begin{array}{c}\text { Pendapatan } \\
\text { Bersih }\end{array}$ \\
\hline & \multicolumn{4}{c}{$---------~ R p /$ musim } & --------- \\
Minapadi & 26.136 .530 & 12.545 .661 & 11.417 .133 \\
Monokultur Padi & 14.208 .627 & 5.258 .216 & 7.564 .842 \\
\hline
\end{tabular}

Sumber: Data primer penelitian yang telah diolah, 2019 


\section{Profitabilitas}

Profitabilitas merupakan rasio pengukur tingkat kelayakan usahatani. Profitabilitas juga sebagai alat ukur penggunaan aktiva kemampuan menghasilkan keuntungan selama periode tertentu. Profitabilitas dihitung dari perbandingan pendapatan bersih dengan total biaya mengusahakan. Profitabilitas minapadi sebesar 77,69\% yang artinya setiap Rp 100 biaya dikeluarkan untuk budidaya minapadi akan diperoleh profit $77,69 \%$. Profitabilitas monokultur padi sebesar $142,86 \%$ yang menunjukkan setiap Rp 100 biaya dikelurkan akan diperoleh profit $142,86 \%$. Nilai profitabilitas minapadi lebih kecil daripada profitabilitas monokultur padi, hal ini dipengaruhi oleh komponen pembentuk nilai profitabilitas berupa biaya dan pendapatan bersih. Salah satu penyebab biaya tinggi adalah input produksi minapadi yang lebih besar dari monokultur padi. Biaya minapadi bertambah pada biaya perawatan dan pemanenan ikan, pengolahan lahan untuk budidaya ikan, serta benih ikan dan pakan ikan. Nilai profitabilitas monokultur padi dan minapadi telah melebihi suku bunga deposito bank sebesar 5,5\% (suku bunga deposito bank BRI tahun 2018), dapat dikatakan kedua usahatani tersebut profitabel atau layak untuk dilaksanakan dan dikembangkan. Sesuai pernyataan Ambarsari et al. (2015) yang menyatakan bahwa kelayakan usaha dapat dilihat dari nilai profitabilitas yang dibandingkan dengan niai suku bunga deposito bank. Profitabilitas minapadi dan monokultur padi yang lebih besar dari suku bunga deposito bank menunjukkan investasi pada kedua usahatani tersebut menghasilkan profit yang lebih tinggi daripada investasi di bank.

\section{Uji Normalitas}

Nilai normalitas diperoleh dari nilai signifikansi hasil uji SPSS. Data berdistribusi normal jika signifikansi uji SPSS $\geq 0,05$ dan data tidak berdistribusi normal jika nilai signifikansi uji SPSS $<0,05$. Nilai normalitas pendapatan minapadi 0,026 dan pendapatan monokultur padi 0,013 , sedangkan profitabilitas minapadi 0,999 dan profitabilits monokultur padi 0,67. Hasil uji normalitas data pendapatan minapadi dan monokultur padi kurang dari taraf signifikansi 0,05 yang artinya data tidak berdistribusi normal. Nilai signifikansi data profitabilitas minapadi dan monokultur padi lebih dari 0,05, artinya data berdistribusi normal. Hasil distribusi data akan digunakan dalam pemilihan jenis uji parametrik atau non parametrik.

\section{Uji Beda Pendapatan Bersih Minapadi dan Monokultur Padi}

Uji beda wilcoxon digunakan untuk menguji perbedaan pendapatan bersih minapadi dan monokultur padi karena data tidak berdistribusi normal. Hasil uji diperoleh nilai signifikansi atau Asymp sig (2 tailed) sebesar 0,000 < 0,05 yang artinya $\mathrm{HO}$ ditolak dan $\mathrm{Hl}$ diterima. $\mathrm{Hl}$ yang diterima menunjukkan pendapatan bersih minapadi lebih besar daripada pendapatan bersih monokultur padi. Pendapatan bersih minapadi lebih besar dari pendapatan bersih monokultur menunjukkan minapadi dapat memberikan keuntungan lebih bagi usahatani petani. Pendapatan bersih yang lebih besar mampu menjadi salah satu motivasi keberlanjutan usahatani minapadi. 


\section{Uji Beda Profitabilitas Minapadi dan Monokultur Padi}

Uji beda paired sample $t$ test untuk menguji hipotesis kedua karena data berdistribusi normal. Berdasarkan hasil analisis data uji beda paired sample $t$ test diperoleh nilai signifikansi 0,000 < 0,05, artinya HO ditolak dan $\mathrm{Hl}$ diterima. $\mathrm{H} 1$ diterima menunjukkan ada perbedaan yang signifikan antara profitabilitas minapadi dan monokultur padi. Profitabilitas kedua usahatani memiliki perbedaan yang signifikan, dimana profitabilitas monokultur lebih tinggi daripada profitabilitas minapadi. Tingginya profitabilitas monokultur menunjukkan perbandingan pendapatan yang tinggi dan biaya yang rendah dalam pelaksanaannya. Petani yang telah lama melaksanakan monokultur padi mampu memahami dan mengatasi masalah lapangan saat pelaksanaan budidaya, mampu memilih input-input produksi yang sesuai dan dibutuhkan sehingga menekan biaya, serta didukung produktivitas lahan yang baik. Hal-hal tersebut menjadi faktor yang menyebabkan nilai profitabilitas tinggi. Profitabilitas minapadi yang lebih rendah dari monokultur, kemungkinan dapat disebabkan oleh pelaksanaannya yang baru pertama kali bagi petani sehingga belum menguasai budidaya secara maksimal serta tingkat biaya yang tinggi akibat penambahan input produksi serta nilai input yang tinggi.

\section{Uji Beda Profitabilitas Minapadi dan Suku Bunga Deposito Bank}

Uji beda one sample $t$ test digunakan untuk menguji perbedaan profitabilitas minapadi dan suku bunga deposito karena data berdistribusi normal. nilai signifikansi (P value) sebesar 0,000000000009 < 0,05 yang artinya HO ditolak dan H1 diterima. Hl diterima artinya profitabilitas minapadi lebih besar dari nilai pembanding berupa suku bunga deposito bank senilai 5,5\% (Suku Bunga Deposito BRI 2018). Profitabilitas minapadi yang lebih besar dari suku bunga deposito bank menunjukkan penggunaan dana untuk investasi usahatani minapadi akan menghasilkan profit yang lebih besar daripada deposito di bank. Nilai profitabilitas minapadi menggambarkan usahatani minapadi layak untuk dikembangkan. Nilai suku bunga deposito bank yang digunakan sebagai standar adalah BRI karena BRI tersebar hampir di seluruh tingkat kecamatan sehingga akses petani dengan bank tersebut lebih dekat.

\section{KESIMPULAN DAN SARAN}

\section{Kesimpulan}

Berdasarkan penelitian analisis pendapatan usahatani minapadi di Kabupaten Sukoharjo diperoleh hasil bahwa pendapatan bersih minapadi senilai Rp $11.417 .133 /$ musim/4.152 $\mathrm{m}^{2}$ lebih besar dari pendapatan bersih monokultur padi senilai Rp 7.564.842/musim/4.152 $\mathrm{m}^{2}$, profitabilitas minapadi sebesar 77,69\% dan monokultur padi sebesar $142,86 \%$. berbeda secara signifikan dan profitabilitas minapadi lebih besar dari suku bunga deposito bank yaitu 5,5\%.

\section{Saran}

Sebaiknya biaya untuk usahatani minapadi diminimalisir agara pendapatan bersih dan profitabilitas yang dihasilkan lebih tinggi. Minimalisir biaya dapat dilakukan dengan penggunaan mesin untuk panen dan tanam yang lebih murah dibandingkan tenaga kerja. 


\section{DAFTAR PUSTAKA}

Akbar, A. 2017. Peran Intensififikasi Mina Padi Dalam Menambah Pendapatan Petani Padi Sawah Digampong Gegarang Kecamatan Jagong Jeget Kabupaten Aceh Tengah. J. S. Pertanian. 1: 28-38.

Ambarsari, W., V. D. Y. B. Ismadi., dan A. Setiadi. 2015. Upaya Pengembangan Agribisnis Padi (Oryza Sativa L.) Di Kabupaten Indramayu. Jurnal Ekonomi \& Kebijakan Publik. 3 (1): 67-82.

Badan Pusat Statistika. 2018. Kabupaten Sukoharjo Dalam Angka. Sukoharjo: BPS Kabupaten Sukoharjo.

Cahyanti, W. V. A. Prakoso., O. Z. Arifin dan I. I. Kusmini. 2014. Produksi Ikan Unggul Di Lahan Minapadi Secara Intensif. J. Sains Natural Universitas Nusa Bangsa. 4 (1): 26-33.

Ekowati, T., D. Sumarjono dan E. Prasetyo. 2014. Usahatani. Semarang: Fakultas Peternakan dan Pertanian Universitas Diponegoro.

Ghozali, I. 2011. Analisis Multivariat Dengan Program IBM SPSS 19. Semarang: Badan Penerbit Universitas Diponegoro.

Julistia, D. R. 2017. Analisis Pendapatan Usahatani Minapadi Di Desa Margoluwih Kecamatan Seyegan Kabupaten Sleman. [Skripsi]. Bogor: Institut Pertanian Bogor.

Lantarsih, R. 2017. Pengembangan 'Minapadi Kolam Dalam' Di Kabupaten Sleman. AGRARIS: Journal of Agribusiness and Rural Development Research 2 (1): 1727.

Pratiwi, P. A dan M. Rondhi. 2018. Land Ownership and Farm Income Distribution Among Farmers in The Peri-Urban Area in Jember (Distribusi Kepemilikan Lahan Pertanian Dan Pendapatan Usahatani Di Wilayah Perkotaan Kabupaten Jember). SEPA: Jurnal Sosial Ekonomi Pertanian Dan Agribisnis $15(1): 81$.

Saputra, A. B., A. Astuti dan S. Widiatmi. 2017. Perbandingan Pendapatan Usahatani Padi Menurut Sistem Mina Padi Dan Non Mina Padi Di Kecamatan Pakem, Kabupaten Sleman, D.I. Yogyakarta. J. Ilmiah Agritas. 1 (2): 1-6.

Tysno, L. F. I. 2018. Analisis Pendapatan Usahatani Minapadi. [Skripsi]. Bogor: Institut Pertanian Bogor. 